\title{
Virology, pathophysiology and neuroinvasion mechanisms of SARS-CoV-2: A mini literature review
}

\author{
Arash Pourgholaminejad' ${ }^{1}$, Samaneh Kazemi², Alia Saberi ${ }^{3}$ \\ ${ }^{1}$ Department of Immunology, School of Medicine, Guilan University of Medical Sciences, Rasht, Iran \\ ${ }^{2}$ Deputy of Research and Technology, Guilan University of Medical Sciences, Rasht, Iran \\ ${ }^{3}$ Department of Neurology, Poursina Hospital, School of Medicine, Guilan University of Medical Sciences, Rasht, Iran
}

\begin{abstract}
Coronavirus-2 (CoV-2) is known as a respiratory pathogen for which the accumulation of evidence suggest that the severe acute respiratory syndrome (SARS) can cause critical pathologies in vulnerable patients. The coronavirus disease-2019 (COVID-19) pandemic is an example of a multi-systemic infectious disease. In addition of respiratory manifestations and severe pneumonia related to COVID-19, The SARS-CoV-2 can penetrate into the central nervous system (CNS) and participate in the induction of neurological disorders and promote some neuropathies. Knowledge of the spectrum of SARS-CoV-2-associated pathophysiology and neuroinvasion pathways will lead to improved clinical outcomes and better treatment algorithms. The aim of this review is to summarize available knowledge on the identification of virology, neuroinvasion mechanisms and the pathophysiology of SARS-CoV-2 in the CNS.
\end{abstract}

Keywords: SARS-CoV-2, central nervous system, pathophysiology

\section{INTRODUCTION}

Several cases of unknown origin pneumonia were detected in Wuhan, Hubei province of China in December 2019 and a new zoonotic-origin coronavirus named 2019 novel coronavirus (2019-nCoV) was isolated in January 2020 [1,2]. On March 11, 2020 the World Health Organization (WHO) declared the COVID-19 pandemic and among 167 million total cases worldwide, more than 3.48 million people have died from critical COVID-19 until now (May-27, 2021) [3,4].

There are records of a number of mild to serious neurological syndromes in SARS-CoV-2 infected patients, including headache, anosmia, seizures, coma, encephalitis, guillain-barre syndrome, and acute cerebrovascular incidents (ischemic stroke, intracerebral hemorrhage and cerebral venous sinus thrombosis) [5]. Early reports from China indicated that up to $36 \%$ of COVID-19 patients may experience neurological manifestations [6]. Although, in this review we will report the relationship between
COVID-19 and the nervous system. Accordingly, mechanisms associated to neuroinvasion and pathogenesis of SARS-CoV-2 infection will be discussed.

\section{VIROLOGY OF SARS-COV-2}

Based on clinical manifestations, blood testing, and chest radiographs, the COVID-19 was diagnosed as virus-induced pneumonia [7]. SARS-CoV-2 was regarded as a member of the $\beta$-CoVs after sequence and evolutionary tree analysis. The CoVs family is a class of single-stranded, positive-sense enveloped RNA viruses with a wide range of natural roots. Respiratory, gastrointestinal, hepatic and neurological disorders may be caused by these virus families. According to genotype and serology, the CoVs families are classified into four subgroups: $\alpha-, \beta-, \gamma$ - and $\delta$-CoVs. Infections of human $\mathrm{CoV}$ are caused by $\alpha$ and $\beta$-CoVs. SARS-CoV and MERS-CoV are members of $\beta$-CoVs. Genome-wide phylogenetic analysis indi- 
cates that SARS-CoV-2 shares $79.5 \%$ and $50 \%$ sequence identity to SARS and MERS coronaviruses, respectively [8].

\section{PATHOPHYSIOLOGY OF NEUROLOGICAL DAMAGES RELATED TO COVID-19}

\section{Direct viral injury}

In nervous system tissue samples (such as cerebrospinal fluid or brain), the genetic material and even proteins of different viruses can also be found, indicating that viruses can enter the nervous system directly and cause nerve damage $[9,10]$. The cerebral vessels come into close contact with viruses and are influenced by viral infection and systemic inflammatory changes [11]. There is currently no conclusive evidence that coronaviruses cause inflammatory neuromuscular diseases through direct invasion of peripheral nerves or muscles or through molecular mimicry. The majority of COVID-19 patients' neurologic symptoms tend to be indirect and as a consequence of bystander neuron damage [12].

\section{Cytokine storm}

The cytokine storm could play an important role in the immunopathology of COVID-19, as in a serious influenza infection [13]. In COVID-19 patients, pro-inflammatory cytokines and chemokines including tumor necrosis factor (TNF)- $\alpha$, interleukin $1 \beta$ (IL-1 $\beta$ ), IL-6, granulocyte colony stimulating factor, interferon gamma-induced protein-10, monocyte chemo-attractant protein-1 (MCP-1), and macrophage inflammatory protein 1- a have been shown to be significantly elevated [14,15]. In addition, in critical form of COVID-19, lymphopenia in both CD4+ helper T cells and CD8+ cytotoxic T cells, as well as high production of IL-6 and IL-10 was seen [16]. The permeability of the blood-brain barrier (BBB) is increased after the emergence of hyper-inflammation during the cytokine storm. Then CD68+ monocyte/macrophages and CD3+ $\mathrm{T}$ cells migrate into the infected brain and a large number of inflammatory cytokines are released, which promotes thrombosis and stroke [17,18]. Viral sepsis is induced by disseminated COVID-19's direct assault on various tissues, immunological pathogenesis mediated by systemic cytokine storms, and microcirculation dysfunction [13].

\section{Unintended host immunity and systematic disease effects}

Infectious diseases, primarily by molecular mimicry, have long been seen as one of the causes for autoimmune and auto-inflammatory diseases. The number of complications following SARS-CoV-2 infection in adults is wider than in children and in- volves autoimmune disorders, but their occurrence is too rare for adults [19]. Emerging reports indicate that infection with SARS-CoV-2 can lead to autoimmune and auto-inflammatory diseases in children, such as pediatric multi-systemic inflammatory syndrome (PIMS; including Kawasaki-like disease, Kawasaki disease shock syndrome, toxic shock syndrome, myocarditis, and macrophage activation syndrome) [20-25].

\section{Systematic disease effects}

A systemic disease is a disease that affects the body as a whole, or affects a variety of organs and tissues [26]. Several experiments have been carried out in order to better understand this disease's pathogenesis and clinical aspects. It seems that due to the direct impact of the virus and its triggered widespread inflammatory response, SARS-CoV-2 affects almost all body organs including respiratory system, cardiovascular system, urinary system, hematopoietic system, gastrointestinal tract system plus hepatic and pancreatic involvement, and nervous system [22].

\section{NEUROINVASION MECHANISMS}

\section{Trans-synaptic spread}

There is growing evidence of the invasion of peripheral nerve terminals by human and non-human CoV, retrograde spread through nerve synapses, and access to the CNS [23,27]. Retrograde trans-synaptic spread with either endocytosis or exocytosis and quick axonal transport of vesicles along the microtubules are proposed mechanisms for moving coronaviruses [7]. Studies using a variety of tracing molecules have shown strong transsynaptic marking after intracellular injection, implying that interneuronal transfer occurs at synaptic junctions. However, the transsynaptic mechanism is complex and difficult to research, in part due to the synapse's small yet complex structure and the lack of reliable tracing methods [28]. The transsynaptic exchanges of coronaviruses can be facilitated by membranous coating-mediated endo/exocytosis, according to Li et al. They also speculated that the transsynaptic pathway may be modified to work with larger granular materials like viruses [28].

\section{Olfactory nerve}

A common cause of olfactory dysfunction is viral upper respiratory tract infection, in part because the olfactory epithelium is situated adjacent to the respiratory epithelium, the site of replication of several viruses that cause upper respiratory tract infection, and that the environment is directly accessible to olfactory neurons. The increasing amount of in- 
ternet searches that inquire about smell loss is closely associated with the increased prevalence of COVID-19 [29]. Therefore, another possible mechanism for SARS-CoV-2 entry to the CNS is direct entry through the olfactory nerve [7]. Olfactory and gustatory functional dysfunction has been identified as being a COVID-19 characteristic and may be a significant clinical outcome indicator [30].

\section{Blood-brain barrier spread}

By passing through vascular endothelial cells (all endothelial cells express ACE-2) or by passing virus infected leukocytes through the BBB, SARS-CoV-2 may invade the CNS [7]. Both mechanisms are described below.

\section{Connection to angiotensin-converting enzyme 2 (ACE2)}

The presence of ACE-2 receptors is now understood to be important for the cellular entry of extreme SARS-CoV-2. On the viral surface, the spike proteins bind to the host cells with the ACE-2 receptor and enter the cells [31]. Viral cellular tropism is determined by the presence of ACE- 2 on tissues. In humans, ACE-2 receptors, are expressed in several tissues such as the airway epithelium, lung parenchyma, renal cells, small intestine, vascular endothelium, and CNS [32].

SARS-CoV-2 and its structure have clear similarities to other coronavirus species whith discovered until now, and the identified SARS-CoV-2 genome sequence closely resembles other beta-coronaviruses including SARS-CoV-1 [33,34]. SARS-CoV-1 and SARS-CoV-2 using the same ACE2 receptor for cell entry $[33,35]$, while SARS-CoV-2 has a higher binding affinity for ACE2 than SARS-CoV-1, this could explain why SARS-CoV-2 is more transmissible [36]. ACE2 binds to SARS-CoV-2 with an affinity of $15 \mathrm{nM}$, approximately 10-20-times higher than that of SARS-CoV-1, and this might clarify its greater virulence [37]. Cell entry also requires priming of the $S$ protein by the cellular serine protease TMPRSS2 or other proteases, which results in S protein cleavage at the S1/S2 and S2' sites, allowing the fusion of viral and cellular membranes, a process guided by the $\mathrm{S} 2$ subunit. The co-expression of ACE2 and TMPRSS2 is needed to complete this entry procedure. Most of the amino acid residues needed for SARS-S protein binding to ACE2 was conserved in SARS-2-S protein, according to an analysis of the receptor binding motif (RBM), a portion of the RBD that connects with ACE2 [19].

\section{Through infected leukocytes}

Increased blood-brain barrier permeability caused by systemic inflammation in the COVID-19 infection could allow infected immune cells to pass through the CNS and thus to enter the virus [38]. Patients infected with SARS-CoV-2 that develop cerebrovascular disease often develop complications such as hypertension and other stroke risk factors. Pro-inflammatory modifications during SARS-CoV-2 infection are linked to stroke risk factors, and leukocyte activation and subsequent cerebrovascular thrombosis have been observed in response to inflammatory stimulation. BBB disruption is caused by the aggregation of inflammatory immune cells in the vascular wall, which can lead to thrombosis and increase the risk of stroke [17].

\section{Vascular endothelium}

Not only lung tissue, but also vascular endothelium is the target of SARS-CoV-2 because vascular endothelium has ACE2, like lung tissue. There are several roles in the vascular endothelium and it is the only place where the von Willebrand factor (VWF) is processed. During its infection, SARS-CoV-2 also induces thrombosis attacks. Angiotensin II levels are elevated by blocking of ACE2 by SARS-CoV-2. In both the vascular endothelium and platelets, angiotensin II stimulation and local stimuli such as $\mathrm{H}+$ ion and hypoxia activate $\mathrm{Na}+/ \mathrm{H}+$ exchanger (NHE). By inducing NHE activation, SARS-CoV-2 can lead to thrombosis [39]. The high affinity of SARS-CoV-2 to the ACE2 receptor and probably other receptors still to be identified could lead to severe renin-angiotensin-aldosterone system (RAAS) dysfunction, as ACE2 is a key counter-regulator in this pathway. ACE2 cleaves angiotensin II into angiotensin I, which has vasodilator, antiproliferative, and antifibrotic effects [40]. At least partly, the organotropism of SARS-CoV-2 may be clarified by the hypothesis that the virus uses RAAS as a vehicle for its volatile early assault on human cells [41].

\section{CONCLUSIONS}

Awareness of the spectrum of pathophysiology and neuroinvasion mechanisms associated with SARS-CoV-2 will lead to improved clinical results and better algorithms for treatment. As regards, the SARS-CoV-2 pandemic is an example of a multi-systemic infectious disease. 


\section{REFERENCES}

1. Guan WJ, Ni ZY, Hu Y, Liang WH, Ou CQ, He JX, Liu L, Shan H, Lei CL, Hui DS, Du B. Clinical characteristics of coronavirus disease 2019 in China. N Engl J Med. 2020 Apr 30;382(18):1708-1720.

2. Zhou P, Yang XL, Wang XG, Hu B, Zhang L, Zhang W, Si HR, Zhu Y, Li B, Huang $\mathrm{CL}$, Chen HD. A pneumonia outbreak associated with a new coronavirus of probable bat origin. Nature. 2020 Mar;579(7798):270273.

3. Long QX, Liu BZ, Deng HJ, Wu GC, Deng K, Chen YK, Liao P, Qiu JF, Lin Y, Cai XF, Wang DQ. Antibody responses to SARS-CoV-2 in patients with COVID-19. Nat Med. 2020 Jun;26(6):845-848.

4. Coronavirus disease (COVID-19). 2020; Available at: https://www.who. int/emergencies/diseases/novel-coronavirus-2019.

5. Frontera J, Mainali S, Fink EL, Robertson CL, et al. Global consortium study of neurological dysfunction in COVID-19 (GCS-NeuroCOVID): study design and rationale. Neurocrit Care. 2020 Aug;33:25-34.

6. Mao L, Jin H, Wang M, Hu Y, Chen S, et al. Neurologic manifestations of hospitalized patients with coronavirus disease 2019 in Wuhan, China. AMA Neurol. 2020 Jun 1;77(6):683-90.

7. Huang C, Wang Y, Li X, Ren L, Zhao J, et al. Clinical features of patients infected with 2019 novel coronavirus in Wuhan, China. Lancet. 2020 Feb 15;395(10223):497-506.

8. Jin Y, Yang H, Ji W, Wu W, Chen S, Zhang W, Duan G. Virology, epidemiology, pathogenesis, and control of COVID-19. Viruses. 2020 Apr;12(4):372.

9. Dubé $M$, Le Coupanec A, Wong AH, Rini JM, Desforges M, Talbot PJ. Axonal transport enables neuron-to-neuron propagation of human coronavirus OC43. J Virol. 2018 Sep 1;92(17):e00404-18.

10. Arbour N, Day R, Newcombe J, Talbot PJ. Neuroinvasion by human respiratory coronaviruses. J Virol. 2000 Oct 1;74(19):8913-8921.

11. Pugin D, Vargas MI, Thieffry C, Schibler M, et al. COVID-19-related encephalopathy responsive to high-dose glucocorticoids. Neurology. 2020 Sep 22;95(12):543-546.

12. Azizi SA. Neurological injuries in COVID-19 patients: direct viral invasion or a bystander injury after infection of epithelial/endothelial cells. J Neurovirol. 2020;26(5):631-641.

13. Zubair AS, McAlpine LS, Gardin T, Farhadian S, Kuruvilla DE, Spudich S. Neuropathogenesis and neurologic manifestations of the coronaviruses in the age of coronavirus disease 2019: a review. JAMA Neurol. 2020 Aug 1;77(8):1018-1027.

14. Klopfenstein T, Kadiane-Oussou NJ, Toko L, Royer PY, Lepiller Q, Gendrin V, Zayet S. Features of anosmia in COVID-19. Med Mal Infect. 2020 Aug 1;50(5):436-439.

15. Paolo G. Does COVID-19 cause permanent damage to olfactory and gustatory function?. Med Hypotheses. 2020 Oct 1;143:110086.

16. Wan S, Yi Q, Fan S, Lv J, Zhang X, Guo L, Lang C, Xiao Q, Xiao K, Yi Z, Qiang M. Characteristics of lymphocyte subsets and cytokines in peripheral blood of 123 hospitalized patients with 2019 novel coronavirus pneumonia (NCP). MedRxiv. 2020 Jan 1.

17. Fan $H$, Tang $X$, Song $Y$, Liu $P$, Chen Y. Influence of COVID-19 on Cerebrovascular Disease and its Possible Mechanism. Neuropsychiatr Dis Treat. 2020;16:1359-1367.

18. Fugate JE, Lyons JL, Thakur KT, Smith BR, Hedley-Whyte ET, Mateen FJ. Infectious causes of stroke. Lancet Infect Dis. 2014 Sep 1;14(9):8698680 .

19. Hoffmann M, Kleine-Weber H, Schroeder S, et al. SARS-CoV-2 Cell Entry Depends on ACE2 and TMPRSS2 and Is Blocked by a Clinically Proven Protease Inhibitor. Cell. 2020 Apr 16;181(2):271-280.e8.

20. Zirpe KG, Dixit S, Kulkarni AP, Sapra H, et al. Pathophysiological Mechanisms and Neurological Manifestations in COVID-19. Indian J Crit Care Med. 2020 Oct;24(10):975-980.

21. Spiegel M, Schneider K, Weber F, Weidmann M, Hufert FT. Interaction of severe acute respiratory syndrome-associated coronavirus with dendritic cells. .J Gen Virol. 2006 Jul 1;87(7):1953-1960.
22. Wu Y, Xu X, Chen Z, Duan J, Hashimoto K, Yang L, Liu C, Yang C. Nervous system involvement after infection with COVID-19 and other coronaviruses. Brain Behav Immun. 2020 Jul 1;87:18-22.

23. Cure E, Cure MC. COVID-19 May Predispose to Thrombosis by Affecting Both Vascular Endothelium and Platelets. Clin Appl Thromb Hemost. 2020 Jul 3;26: 1076029620933945.

24. Vaduganathan M, Vardeny O, Michel T, McMurray JJ, Pfeffer MA, Solomon SD. Renin-Angiotensin-Aldosterone System Inhibitors in Patients with Covid-19. N Engl J Med. 2020 Apr 23;382(17):1653-1659.

25. Ackermann M, Verleden SE, Kuehnel M, et al. Pulmonary Vascular Endothelialitis, Thrombosis, and Angiogenesis in Covid-19. N Engl J Med. 2020 Jul 9;383(2):120-128.

26. Koyuncu O, Hogue I, Enquist L. Virus infections in the nervous system. Cell Host Microbe, 2013 Apr 17;13(4):379-393.

27. Li H, Liu L, Zhang D, Xu J, Dai H, Tang N, Su X, Cao B. SARS-CoV-2 and viral sepsis: observations and hypotheses. Lancet. 2020 May 9;395(10235):1517-1520.

28. Li YC, Bai WZ, Hirano N, Hayashida T, et al. Neurotropic virus tracing suggests a membranous-coating-mediated mechanism for transsynaptic communication. J Comp Neurol. 2013 Jan 1; 521(1):203-212.

29. Liu J, Li S, Liu J, Liang B, Wang X, et al. Longitudinal characteristics of lymphocyte responses and cytokine profiles in the peripheral blood of SARS-CoV-2 infected patients. EBioMedicine. 2020 May 1;55:102763.

30. Galeotti C, Bayry J. Autoimmune and inflammatory diseases following COVID-19. Nat Rev Rheumatol. 2020 Aug;16(8):413-414.

31. Verdoni L, Mazza A, Gervasoni A, Martelli L, Ruggeri M, Ciuffreda M, Bonanomi E, D'Antiga L. An outbreak of severe Kawasaki-like disease at the Italian epicentre of the SARS-CoV-2 epidemic: an observational cohort study. Lancet. 2020 Jun 6;395(10239):1771-1778.

32. Riphagen S, Gomez X, Gonzalez-Martinez C, Wilkinson N, Theocharis P. Hyperinflammatory shock in children during COVID-19 pandemic. Lancet. 2020 May 23;395(10237):1607-1608.

33. Zhou P, Yang XL, Wang XG, Hu B, Zhang L, et al. A pneumonia outbreak associated with a new coronavirus of probable bat origin. Nature. 2020 Mar;579(7798):270-273.

34. Ather A, Patel B, Ruparel NB, Diogenes A, Hargreaves KM. Coronavirus disease 19 (COVID-19): implications for clinical dental care. J Endod. 2020 May 1;46(5):584-595.

35. Ge XY, Li JL, Yang XL, Chmura AA, Zhu G, et al. Isolation and characterization of a bat SARS-like coronavirus that uses the ACE2 receptor. Nature. 2013 Nov;503(7477):535-538.

36. Wang $Q$, Zhang $Y$, Wu L, Niu S, et al. Structural and functional basis of SARS-CoV-2 entry by using human ACE2. Cell. 2020 May 14; 181(4):894-904.

37. Wrapp D, Wang N, Corbett KS, Goldsmith JA, Hsieh CL, et al. Cryo-EM structure of the 2019-nCoV spike in the prefusion conformation. Science. 2020 Mar 13;367(6483):1260-1263.

38. Belhadjer Z, Méot M, Bajolle F, Khraiche D, et al. Acute heart failure in multisystem inflammatory syndrome in children in the context of global SARS-CoV-2 pandemic. Circulation. 2020 Aug 4;142(5):429-436.

39. Rapid risk assessment: Paediatric inflammatory multisystem syndrome and SARS -CoV-2 infection in children. Available at: https://www.ecdc. europa.eu/en/publications-data/paediatric-inflammatorymultisystem-syndrome-and-sars-cov-2-rapid-risk-assessment.

40. Blumfield E, Levin TL, Kurian J, Lee EY, Liszewski MC. Imaging findings in multisystem inflammatory syndrome in children (MIS-C) associated with coronavirus disease (COVID-19). American Journal of Roentgenology. 2021 Feb 29;216(2):507-517.

41. Dorland WAN. Dorland's Illustrated Medical Dictionary. 28th ed. San Diego, California: Harcourt Brace \& Company, 1994. 